\title{
BMJ Open Critical care nursing role in low and lower middle-income settings: a scoping review
}

\author{
Andy Macey (D) ,1,2 Gerard O'Reilly, ${ }^{1,3}$ Ged Williams, ${ }^{4}$ Peter Cameron ${ }^{1}$
}

To cite: Macey A, O'Reilly G, Williams G, et al. Critical care nursing role in low and lower middle-income settings: a scoping review. BMJ Open 2022;12:e055585. doi:10.1136/ bmjopen-2021-055585

- Prepublication history and additional supplemental material for this paper are available online. To view these files, please visit the journal online (http://dx.doi.org/10.1136/ bmjopen-2021-055585)

Received 21 July 2021 Accepted 07 December 2021

Check for updates

(C) Author(s) (or their employer(s)) 2022. Re-use permitted under CC BY-NC. No commercial re-use. See rights and permissions. Published by BMJ.

${ }^{1}$ School of Public Health and Preventative Medicine, Monash University, Melbourne, Victoria, Australia

${ }^{2}$ The Learning Hub, Peninsula Health, Frankston, Victoria, Australia

${ }^{3}$ National Trauma Research Institute, Melbourne, Victoria, Australia

${ }^{4}$ School of Nursing and Midwifery, Griffith University, Nathan, Queensland, Australia

Correspondence to

Mr Andy Macey;

andy.macey@outlook.com

\section{ABSTRACT}

Objectives A scoping review was conducted to answer the question: How is critical care nursing (CCN) performed in low-income countries and lower middle-income countries (LICs/LMICs)?

Design Scoping review guided by the JBI Manual for Evidence Synthesis.

Data sources Six electronic databases and five webbased resources were systematically searched to identify relevant literature published between 2010 and April 2021. Review methods The search results received two-stage screening: (1) title and abstract (2) full-text screening. For sources of evidence to progress, agreement needed to be reached by two reviewers. Data were extracted and cross-checked. Data were analysed, sorted by themes and mapped to region and country.

Results Literature was reported across five georegions. Nurses with a range formal and informal training were identified as providing critical care. Availability of staff was frequently reported as a problem. No reports provided a comprehensive description of CCN in LICs/LMICs. However, a variety of nursing practices and non-clinical responsibilities were highlighted. Availability of equipment to fulfil the nursing role was widely discussed. Perceptions of inadequate resourcing were common. Undergraduate and postgraduate-level preparation was poorly described but frequently reported. The delivery of short format critical care courses was more fully described. There were reports of educational evaluation, especially regarding internationally supported initiatives.

Conclusions Despite commonalities, CCN is unique to regional and socioeconomic contexts. Nurses work within a complex team, yet the structure and skill levels of such teams will vary according to patient population, resources and treatments available. Therefore, a universal definition of the CCN role in LIC/LMIC health systems is likely unhelpful. Research to elucidate current assets, capacity and needs of nurses providing critical care in specific LIC/ LMIC contexts is needed. Outputs from such research would be invaluable in supporting contextually appropriate capacity development programmes.

\section{INTRODUCTION}

The development of critical care services in lowincome countries and lower middle-income countries (LICs/LMICs) is increasing. ${ }^{1}$ However, little is known regarding capacity and resourcing of these services. ${ }^{2}$ Nurses are

\section{Strengths and limitations of this study}

This is the first review to explore and map the evidence related to how critical care nursing is performed in low-income countries and lower middle-income countries (LICs/LMICs).

- Literature from all georegions where LICs/LMICs are situated was considered for inclusion.

- The inability to translate non-English language documents, mean it is possible that some literature was not captured.

- A lack of literature from Latin American LICs/LMICs in English prevents an accurate picture of critical care nursing in these contexts to be drawn.

key in the successful delivery of critical care in any health system, ${ }^{3}$ yet it is unclear what is currently known regarding their role in LIC/ LMIC health systems.

\section{Background}

The burden of critical illness is substantial in LICs/LMICs ${ }^{245}$ and outcomes are often reported as poorer than in high-resource contexts. ${ }^{5}$ The availability of resources to manage critically ill patients in LICs/LMICs is commonly restricted when compared with high-income countries (HICs). ${ }^{6}$ Access to high-cost technologies and highly trained, specialised teams of healthcare staff available in high-resource health systems ${ }^{1}$ are not always available in a resource-limited setting. ${ }^{7}$ Therefore, the organisation of critical care services needs to be context specific $^{8}$ and will vary across socioeconomic and geo-regional situations.

Nurses are the largest occupational group of healthcare workers globally and are central to meeting the sustainable development goals (SDGs) and universal health coverage (UHC). ${ }^{9}$ Positive associations between the numbers of nurses employed to provide patient care, their level of education and improved patient outcomes are well documented in several HICs ${ }^{10}$ and may be amplified in critical care settings. ${ }^{11}$ In 
response, standards recognising the need for nursing models specific to critical care, extended organisational supports and specialised training to fulfil the critical care nursing (CCN) role are common in HICs. ${ }^{11}{ }^{12}$ Furthermore, the roles and responsibilities of critical care nurses are well described in many HICs. For example, in Australia, nurses routinely undertake all technical and non-technical care of the critically ill patient. They operate and manage therapies such as mechanical ventilation, extracorporeal therapy and intra-aortic balloon pumps. Additionally, they might measure cardiac output from highly technical haemodynamic devices and titrate vasoactive drugs in a semiautonomous fashion. ${ }^{13}$ To date, little work comprehensively reporting the roles, practices and training of critical care nurses in LICs/LMICs appears to be available. Therefore, a scoping review was conducted to map the available evidence, identify the main concepts, sources of data and knowledge gaps and answer the question: How is the CCN role performed in LICs/LMICs?

\section{Objectives}

To elucidate the role of nurses working in critical care contexts in LICs/LMICs, the review aimed to address four subquestions:

1. Who is involved in providing CCN in LICs/LMICs?

2. What are the day-to-day roles and responsibilities of nurses providing critical care in LICs/LMICs?

3. What professional scope of practice is reported for nurses providing critical care in LICs/LMICs?

4. What training and ongoing education are available to nurses providing critical care in LICs/LMICs?

\section{METHODS}

The scoping review was guided by the JBI Manual for Evidence Synthesis ${ }^{14}$ and the Preferred Reporting Items for Systematic Reviews and Meta-Analyses extension for scoping reviews (PRISMA-ScR). ${ }^{15}$ A protocol was developed a priori, published prospectively and can be viewed on the Monash University repository for research data. ${ }^{16}$

\section{Search methods}

A Population Concept Context framework was used to define the evidence to be included in this review (table 1).

Preliminary searches of Ovid Medline, Embase and Emcare were performed to test and refine the search strategy. Final searches were completed on 30 July 2020 and updated on 7 April 2021. Six databases were included: Medline, Embase, Emcare, Global Health, SCOPUS and Web of Science. Limits set in all database searches were publications in the last 10 years (2010 current) and publications in English language. Full details of the search strings employed, additional limits in individual databases and database versions are found in online supplemental file 1. Results from all searches were exported to Endnote citation management software and then imported into Covidence review management software.

Web-based searches were completed on 30 July 2020. Five resources were accessed: Google Scholar, Google, The WHO website, The World Federation of Critical Care Nurses (WFCCN) website and websites of CCN organisations listed as members of the WFCCN. The search in Google scholar was limited to results published in the last 10 years. Consistent with the approach suggested by Pham et al, ${ }^{17}$ the first 100 search results were submitted to an initial two-stage screening process: all titles considered relevant to the research questions were exported to Endnote. Individual titles were resubmitted to Google Scholar, accessed and categorised by type. Evidence that was unrelated to the research questions was removed at this stage. The remaining sources of evidence were imported into Covidence for title and abstract screening.

Searching within the WHO website was undertaken using Google. The WFCCN website was accessed and an additional 11 regional CCN society websites were identified for exploration and data extraction as tier-3 sources. The first 100 search results in google were screened for apparent relevance to the research questions. Duplicate website links and results already discovered through searches were ignored.

\begin{tabular}{lll}
\hline Table 1 & Population Concepts Context framework used to define the evidence included in this review \\
\hline \multicolumn{2}{c}{ Inclusions } & Exclusions \\
\hline Population & Nurses providing critical care or their proxies* & $\begin{array}{l}\text { Visiting international nurses engaged in capacity } \\
\text { development programmes }\end{array}$ \\
Concepts & $\begin{array}{l}\text { Critical care nursing roles, responsibilities, scope of practices, } \\
\text { training and education. }\end{array}$ & \\
Contexts & $\begin{array}{l}\text { Low-income countries and lower middle-income countries as } \\
\text { defined by the World Bank Country and Lending Groups. } \dagger\end{array}$ & $\begin{array}{l}\text { Military hospitals } \\
\text { The pre-hospital setting or during the intra- } \\
\text { hospital transport of patients }\end{array}$
\end{tabular}

${ }^{*}$ Proxies for nurses providing critical care include healthcare workers and lay persons who are not nurses but provide care that might be associated with the nursing role. Examples might include respiratory therapists or healthcare assistants.

†The World Bank Group. World Bank Country and Lending Groups 2020. https://datahelpdeskworldbankorg/knowledgebase/articles/906519world-bank-country-and-lending-groups. 


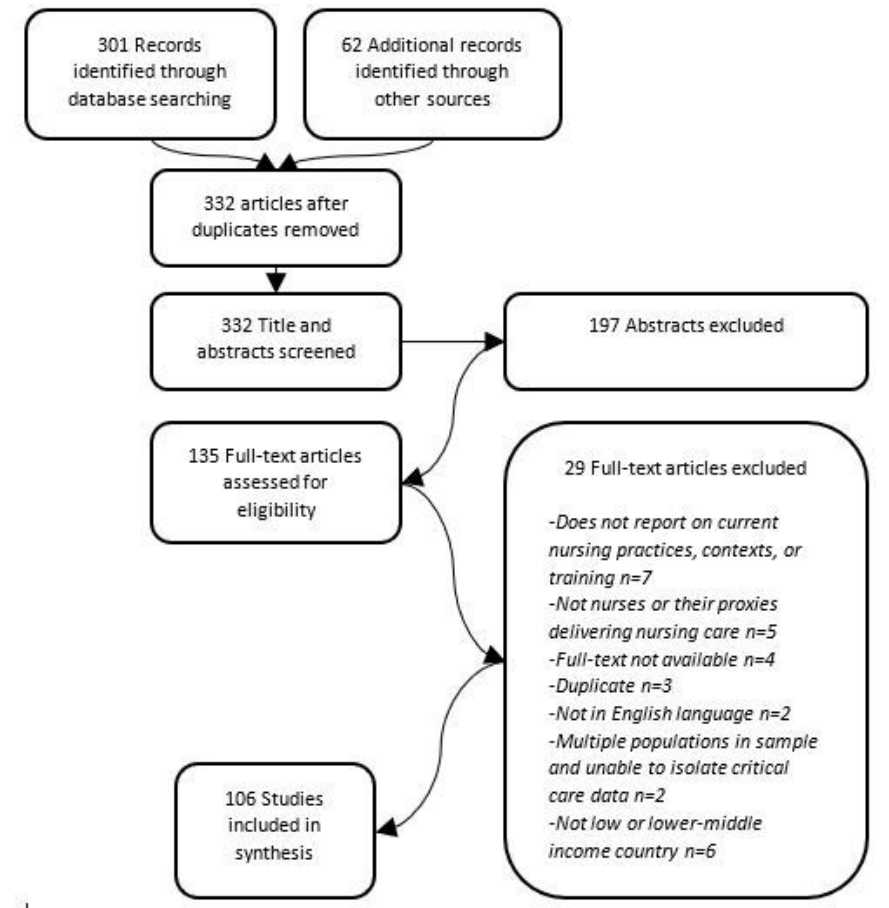

Figure 1 PRISMA flowchart. PRISMA flowchart detailing the results from searching databases and other sources, the number of abstracts screened, the number of full texts accessed, and the number of papers included in the final synthesis. PRISMA, Preferred Reporting Items for Systematic Reviews and Meta-Analyses.

\section{Search outcome}

A total of 361 papers were retrieved from database and web-based searching. Two additional papers were added by hand searching the reference lists of included papers. 31 duplicates were removed. Seventeen web-based sources of evidence were identified.

\section{Quality appraisal}

Guided by Kepes' taxonomy of sources of samples, ${ }^{18}$ two tiers of evidence were considered for inclusion in the screening process: tier-1, the peer-reviewed literature. Tier-2, grey literature produced by a range of bodies such as governments or non-commercial organisations, including conference papers, dissertations and reports. Additionally, tier-3 sources were considered for separate analysis. Tier-3 samples included commercial and personal websites, blogs, and social media. As is conventional in such a broad scoping review, no critical appraisal of the included literature was undertaken. ${ }^{14}$

\section{Data abstraction}

The search results received two-stage screening: (1) title and abstract and (2) full-text screening. For sources of evidence to progress, agreement was needed to be reached by two reviewers. A PRISMA flow diagram demonstrating the screening and selection of literature for inclusion is presented in figure 1.

\section{Synthesis}

Initial extraction was undertaken using a data-charting instrument mapped to the research subquestions. An iterative approach was taken. As new items or themes that provided useful data became apparent, this was discussed by the team and added to the instrument if appropriate. Finally, three extractions were cross checked by another member of the team to determine agreement that all relevant data had been charted.

\section{RESULTS}

Data were predominantly found within peer-reviewed journal articles $(85 \%)$. Other sources of data included conference papers $(9 \%)$, books $(3 \%)$, thesis $(2 \%)$ and reports $(1 \%)$. Half of the included literature reported quantitative research data. Descriptive or descriptive/ correlational methods were the most reported methodologies. Sixteen per cent of included papers reported qualitative results and a further $6 \%$ reported the results of mixed-methods research. The remaining literature encompassed reviews (13\%) or expert opinion/editorial papers (15\%). One book crossed several categories as it included aspects of narrative review, expert opinion and case studies.

The literature focused on countries within five of the seven georegions defined by the World Bank. ${ }^{19}$ The literature distributed across the five georegions were: SubSaharan Africa (SSA) (45\%), South Asia (SA) (24\%), Middle East and North Africa (MENA) (13\%), East Asia and the Pacific (EAP) (10\%) and Latin America and the Caribbean (LAC) (2\%). The remaining $6 \%$ of the literature spoke more broadly to $\mathrm{CCN}$ in resource-limited settings, not specifically within a region.

Several clinical settings were reported as sites where CCN was practised. The distribution is visualised in figure 2.

A large amount of the evidence discussed more than one unit within a health service, for example, multiple intensive care units (ICUs) or a combination of ICUs, paediatric ICUs, neonatal ICUs and non-traditional critical care settings. The remaining literature provided evidence of practice within individual dedicated adult, paediatric, neonatal or mixed units where several patient categories were admitted. A small amount of the literature discussed CCN in emergency departments. Finally, some papers spoke only to critical care undertaken in non-specialist environments such as wards or community health centres.

Tier-3 sources of data included three broad categories of website: (1) CCN society websites or social media pages $(\mathrm{n}=11)$, (2) Blogs $(\mathrm{n}=3)$, and (3) miscellaneous webpages $(n=3)$. The websites of CCN societies and federations included local in-country $(\mathrm{n}=8)$, regional $(\mathrm{n}=2)$ and global $(\mathrm{n}=1)$ level groups.

Three regional CCN groups used Facebook groups as their online medium. The remaining critical care societies and federations used hosted websites. The blog 


\section{Distribution of locations of CCN practice in LICs/LMICS}

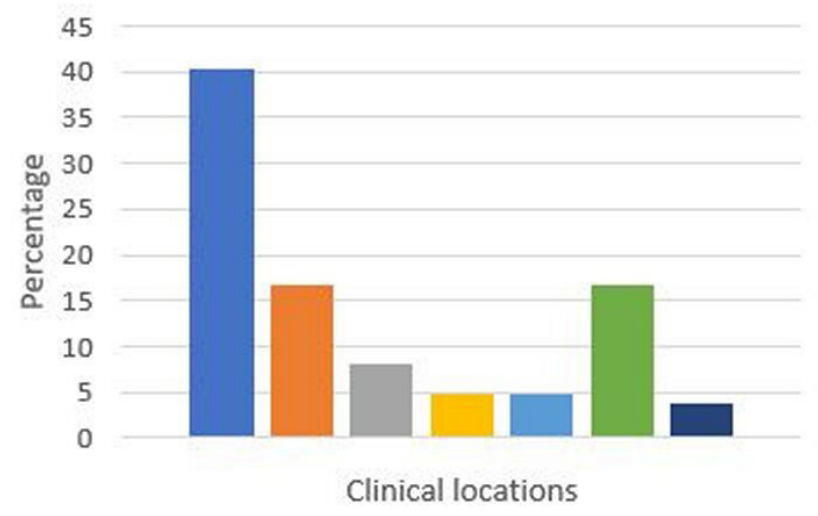

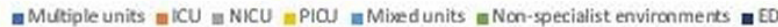

Figure 2 Distribution of locations of CCN practice in LICs/ LMICs. The chart shows the distribution of clinical locations of CCN practice in LICs/LMICs found in the included

literature. CCN, critical care nursing; LICs/LMICs, low-income countries and lower middle-income countries.

entries proved to all be by one author, a CCN educator providing trainings in Nepal. A link was discovered in one of the blog entries to an Non-governmental Organisation providing respiratory care education in LICs/LMICs. All three miscellaneous websites provided evidence of a notfor-profit education company providing free $\mathrm{CCN}$ online educational content to LIC's/LMICs.

Literature providing answers to the research questions is displayed in tables $2-5$. The corresponding references are found in online supplemental file 2. Both positive and negative results were extracted meaning that discussion of a concept being present or not being present were both captured.

Table 2 identifies sources of data related to who provides nursing care to critically ill patients in LICs/LMICs and maps them to region and countries.

Most documents indicated that nurses identified as registered or qualified were engaged in the care of critically ill patients within each region. Many also referred to basic or postbasic qualifications. In several cases, these were limited to identifying basic or postbasic trained nurses as being present, whereas others provided the title of the qualifications (figure 3 ).

A variety of other cadres of healthcare workers and lay persons were also identified as providing aspects or the totality of what might be considered CCN, for example, midwives and respiratory therapists (figure 4).

Table 3 identifies sources of data related to the dayto-day roles and responsibilities of nurses caring for critically ill patients in LICs/LMICs and maps them to regions and countries.
Several specific activities and roles performed by nurses providing critical care in LICs/LMICs were able to be extracted. Some examples included management of airways and mechanical ventilation, care of the septic patient and physiological monitoring. A full overview of the distribution of activities is presented in figure 5 .

Details relating to CCN systems, staffing and capacity were able to be extracted from the literature. Thematically these grouped into four categories: (1) identification of nurse-patient ratios $n=17$, (2) national critical care workforce $n=7$, (3) structure and staffing of unitbased workforce $n=18$, (4) perceptions of insufficient nursing workforce or poor working conditions $n=5$.

Data regarding the availability and utilisation of physical resources to fulfil the CCN role were also extracted and mapped to nine themes: (1) comprehensive lists of available or recommended equipment $n=10$, (2) mechanical ventilators $n=6$, (3) monitoring technologies $n=2$, (4) oxygen or electricity supply $n=1,(5)$ neonatal equipment $\mathrm{n}=2$, (6) personal protective equipment $\mathrm{n}=1$, (7) other therapeutic devices $n=1,(8)$ documentation of care $n=5$, (9) a perceived inadequacy of physical resources $n=9$.

Finally, papers discussing the availability of policies or guidelines were extracted and mapped to themes of locally developed practice guidelines $n=14$, national standards or recommendations for policy $n=4$, the utilisation of international practice guidelines $n=4$, or perceived unavailability or inadequacy of guidelines $n=11$.

Little data were able to be extracted to answer the question: 'What professional scope of practice is reported for nurses providing critical care in LICs/LMICs?' (table 4).

Table 5 identifies sources of data related to the training and continuing education and development of nurses providing critical care in LICs/LMICs and maps them to regions and countries.

Data extracted that identified training could be mapped thematically to (1) education targeting specific practices $n=26$, (2) formal postgraduate study $n=10$, (3) short format courses $n=19$, (4) training courses without a description $\mathrm{n}=4$ and (5) critical care training within the undergraduate curriculum $n=3$. Figure 6 maps these themes to region.

Finally, data were extracted identifying access to educational resources, including the use of information technologies (ITs). Themes included: (1) the availability of peer-reviewed literature $n=4,(2)$ access to locally generated learning materials or education teams $n=3$, (3) access to IT-based education $n=2$, (4) perceived inadequacy of access to educational resources $n=3$.

\section{DISCUSSION}

This is the first review to explore and map the evidence related to how the CCN role is performed in LICs/LMICs. Despite the large number of papers meeting inclusion criteria, few provided a comprehensive description of how CCN is performed in any individual LIC/LMICs or 
Table 2 Literature providing evidence of who is involved in providing nursing care of critical care patients in low income and lower middle-income countries grouped thematically and mapped to region and country

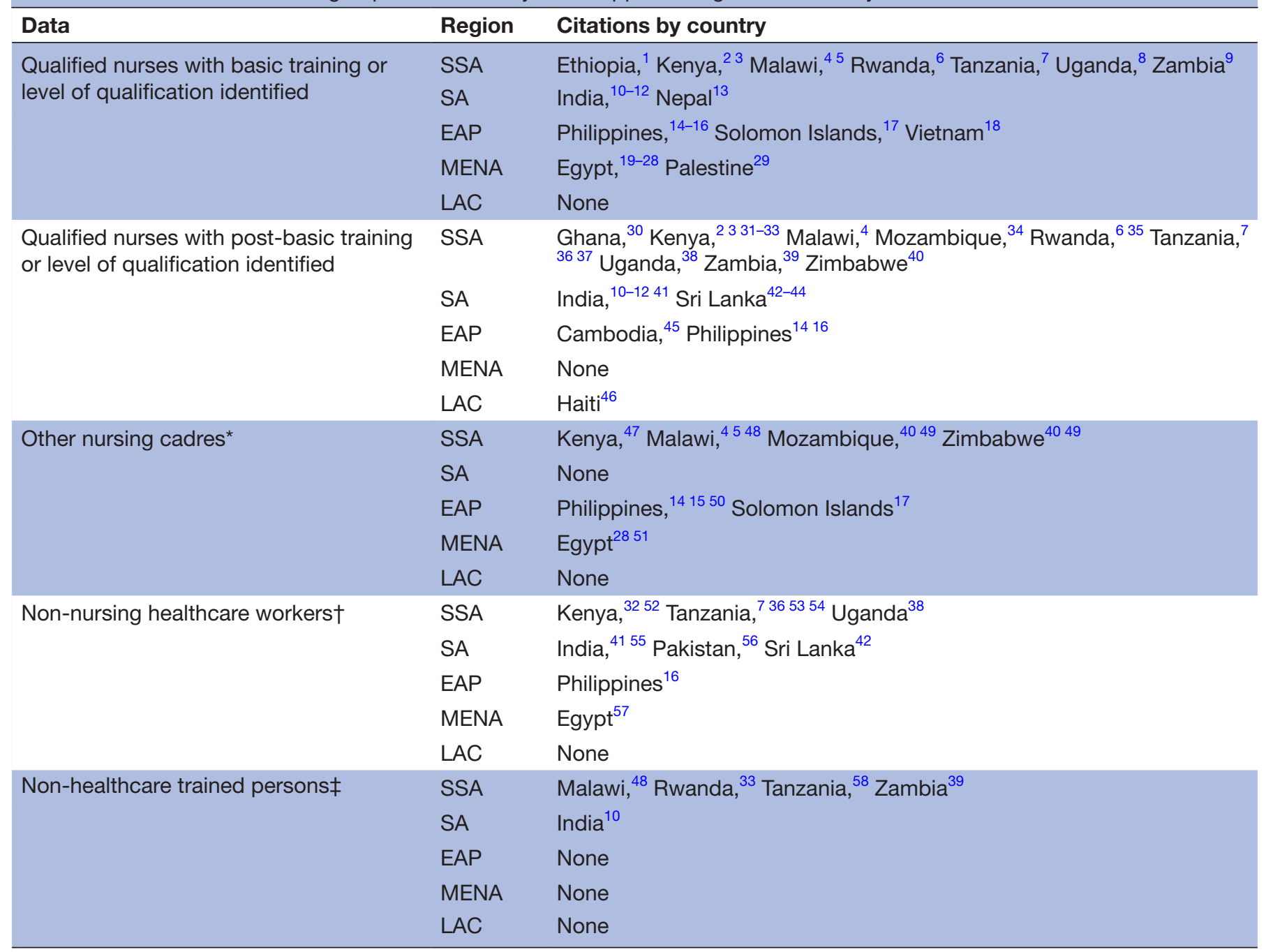

The corresponding references for this table are included in online supplemental file 2.

${ }^{*}$ Other nursing cadres may include but are not limited to student nurses or midwives.

†Non-nursing healthcare workers may include but are not limited to clinical officers, respiratory therapists, or ancillary staff.

$\ddagger$ Non-healthcare trained persons may include but are not limited to families and lay persons.

EAP, East Asia and the Pacific; LAC, Latin America and the Caribbean; Mena, Middle East and North Africa; SA, South Asia; SSA, Sub

Saharan Africa.

region. However, some themes were able to be synthesised from numerous sources and are discussed below.

\section{Who is involved in providing CCN in LICs/LMICs?}

Qualified nurses

Documents indicating that registered or qualified nurses were engaged in the care of critically ill patients were found in all regions except LAC. Where details of basic qualifications of CCNs were provided, they included certificate, diploma and bachelor's degrees with diploma and bachelor's being the most common in many settings. In a large observational study in European hospitals, it was found that for every $10 \%$ increase in nurses holding bachelor's degrees rather than a diploma, a 7\% reduction in 30-day inpatient mortality was measured. ${ }^{10}$ To our knowledge, no similar study has been undertaken in resource-limited health systems offering an opportunity for future research.

\section{Nurses with postbasic qualification in critical care}

The presence of nurses with postbasic training in critical care was reported in all regions but not all countries. In general, postbasic preparation was reported in LMICs but absent in LICs. Most included literature did not identify the numbers or ratios of critical care trained nurses within each country or region. However, in a Kenyan paper, $50 \%$ of nurses working in ICUs were reported as holding postbasic qualification. ${ }^{20}$ Such a ratio achieves the minimum standards recommended in some HICs, for example, Australia. ${ }^{11}$

Guidelines from India recommend that all nurses working in critical care areas hold formal postbasic qualifications ${ }^{3}$ yet even within India, this level of preparation is inconsistent. ${ }^{21}$ 
Table 3 Literature providing evidence of the day-to-day roles and responsibilities providing nursing care of critical care patients in low income and lower middle-income countries grouped thematically and mapped to region and country

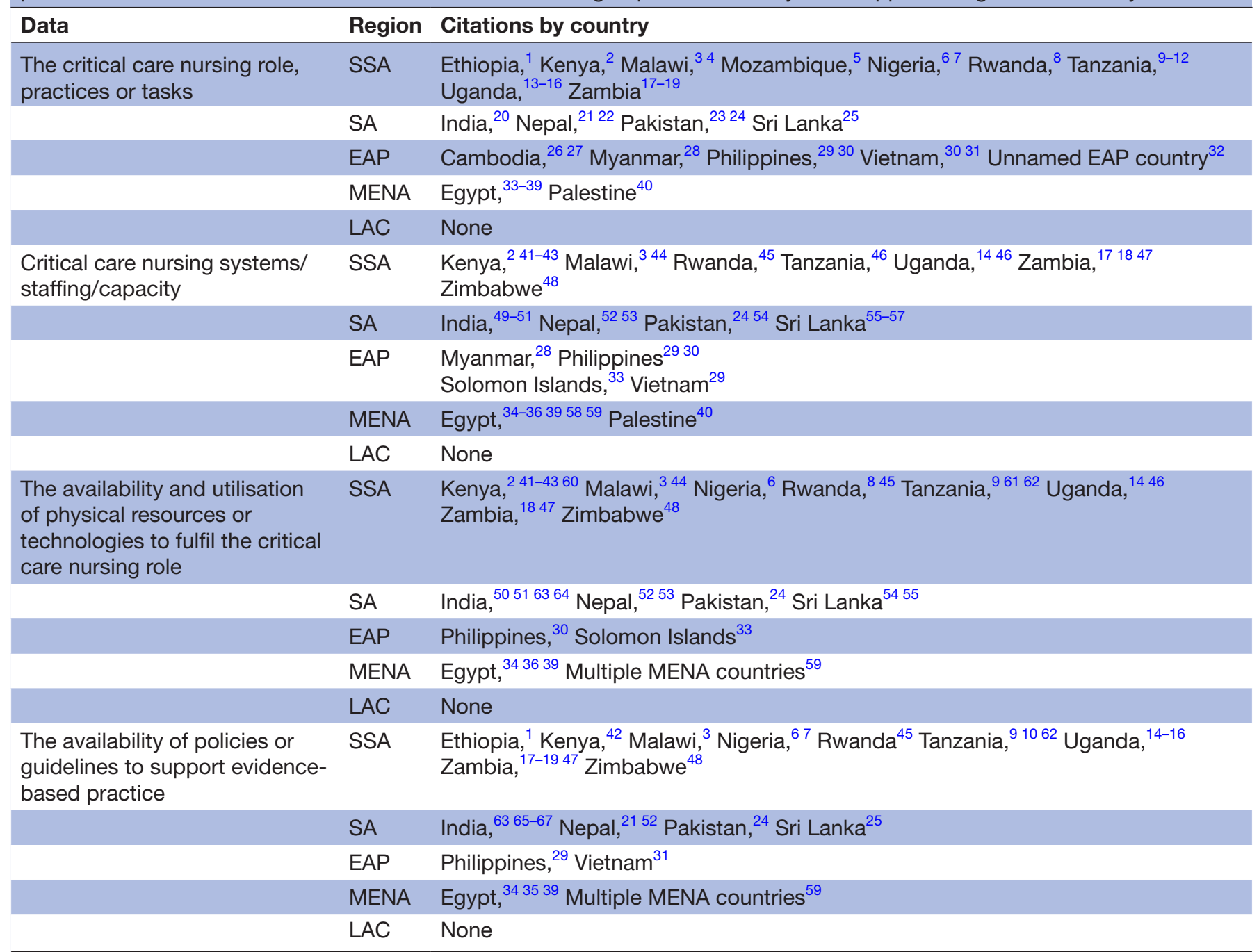

The corresponding references for this table are included in online supplemental file 2.

EAP, East Asia and the Pacific; LAC, Latin America and the Caribbean; Mena, Middle East and North Africa; SA, South Asia; SSA, Sub Saharan Africa.

Literature from Sri Lanka and Zambia described situations where the overall percentage of nurses with postbasic qualification was low. However, it was more common that the nurse in charge held a postbasic qualification. ${ }^{22} 23$ Another situation reported from Zambia suggested that postbasic trained nurses have responsibilities to provide care to deteriorating patients in the wider hospital, reducing the access to trained nurses within the units. ${ }^{24}$

Other cadres of nurses were identified as providing some or all the care commonly associated with the $\mathrm{CCN}$ role. In common, these included enrolled nurses, ${ }^{25}{ }^{26}$ nurse-midwives or midwife technicians. ${ }^{27} 28$ It was also noted that preregistration student nurses were engaged in clinical placements within several ICUs and other critical care settings. ${ }^{27-29}$

\section{Non-nursing cadres}

Papers from SSA, EAP and MENA provided evidence of non-nursing staff providing what might be considered aspects of CCN. Roles included technicians ${ }^{20}$ and personnel described as clinical officers or non-physician clinicians. However, it was not clear in the included papers what constituted a non-physician clinician. ${ }^{30}$ Additionally, nurse anaesthetists ${ }^{32}$ and respiratory therapists ${ }^{33}$ were involved in the care of mechanically ventilated patients. Less clearly defined roles such as healthcare assistants, ${ }^{23}$ ancillary staff and caregivers ${ }^{34-36}$ were also noted.

Non-healthcare trained carers

A small number of documents suggested that lay persons provided nursing care. Some of these discussed the parents' roles in neonatal care c $^{37} 38$ and were similar to practices in HIC neonatal ICUs such as kangaroo care. ${ }^{39}$ Others highlighted the role of lay persons when shortages of nursing staff existed. ${ }^{22}$ A global shortage of healthcare workers, predominately in LMIC contexts, is well recognised. ${ }^{9}$ Urgent work to address this is required if 
Table 4 Literature providing evidence information on registration and professional scope of nurses providing nursing care of critical care patients in low income and lowe middle-income countries grouped thematically and mapped to region and country

\begin{tabular}{lll}
\hline Data & Region & Citations by country \\
\hline $\begin{array}{l}\text { Registration or SSA } \\
\text { professional } \\
\text { standards }\end{array}$ & $\begin{array}{l}\text { Malawi, }{ }^{12} \text { Mozambique, }^{3} \\
\text { Rwanda, }\end{array}{ }^{45}$ Tanzania, ${ }^{6}$ Uganda, \\
& & $\begin{array}{l}{ }^{8} \text { Zambia, }^{9} \text { Multiple SSA } \\
\text { countries }^{10}\end{array}$ \\
& SA & Sri Lanka $^{11}$ \\
EAP & Philippines $^{12}$ \\
MENA & Egypt, ${ }^{13}{ }^{14}$ Palestine $^{15}$ \\
& LAC & None \\
\hline
\end{tabular}

The corresponding references for this table are included in online supplemental file 2 .

The data that were extracted identified nursing registration boards and requirements $n=14$, or professional standards $n=1$.

EAP, East Asia and the Pacific; LAC, Latin America and the Caribbean; Mena, Middle East and North Africa; SA, South Asia; SSA, Sub Saharan Africa.

Table 5 Literature providing evidence of training and continuing education available to nurses providing critical care in low income and lower middle-income countries grouped thematically and mapped to region and country

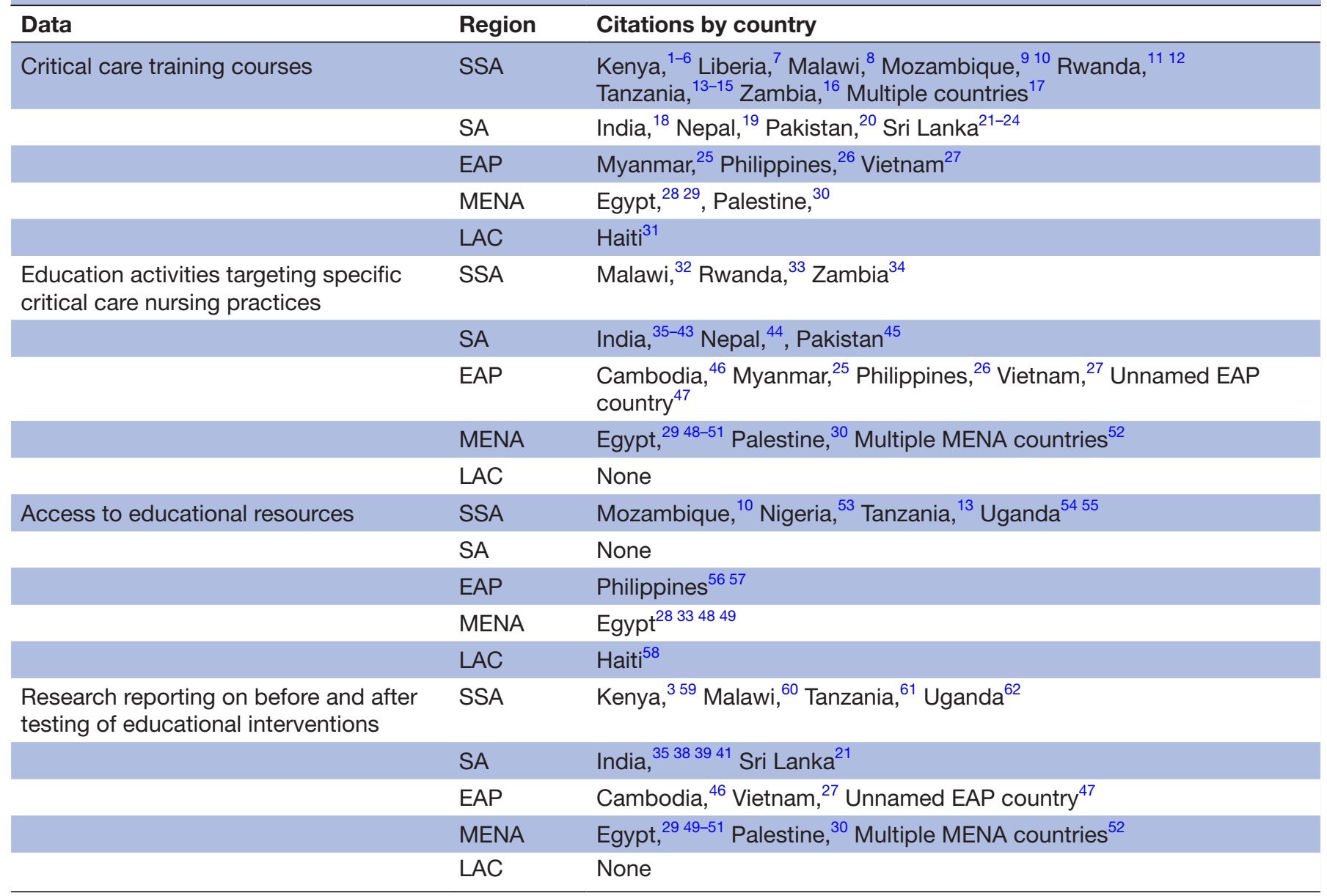

The corresponding references for this table are included in online supplemental file 2.

EAP, East Asia and the Pacific; LAC, Latin America and the Caribbean; Mena, Middle East and North Africa; SA, South Asia; SSA, Sub Saharan Africa.
UHC and the attainment of the $\mathrm{SDGs}^{40}$ are to be met. Although driven by necessity in these examples, multidirectional benefits are reported when families are directly involved in patient care. ${ }^{41}$ However, research in critical care environments is sparce, especially in LIC/LMIC settings. ${ }^{42}$

The day-to-day roles and responsibilities of those providing nursing care of critical care patients in LICs/LMICs

CCN role, practices or tasks

Although specific tasks and roles such as care of the ventilated patient, medication management and clinical education were common, comprehensive description of the role of those providing $\mathrm{CCN}$ within the targeted health systems was not well described. However, three papers presented information on required competencies for critical care nurses, ${ }^{24} 3043$ thus identifying their broad roles, tasks and responsibilities. Further documents described the roles of subspeciality nurses in cardiac-surgical and cardiac-medical units. ${ }^{44}$ 
Distribution of the literature identifying the level

of qualification of nurses providing critical care

in low-income and lower-middle-income

12 countries

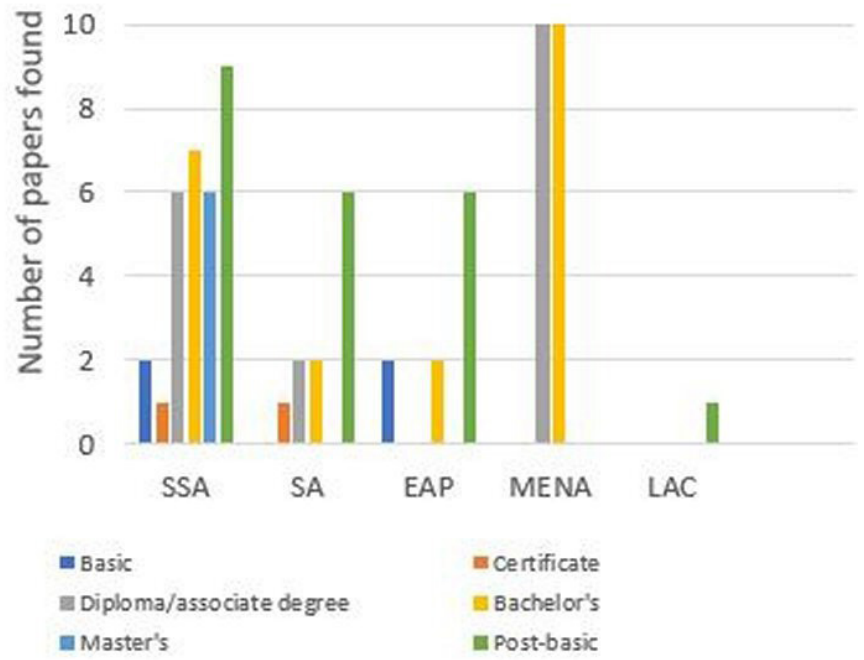

Figure 3 Distribution of the literature identifying the level of qualification of nurses providing critical care in LICs/ LMICs. The chart shows the distribution of included papers that report on or discuss the levels of qualification of nurses providing critical care in LICs/LMICs. EAP, East Asia and the Pacific; LAC, Latin America and the Caribbean; LICs/LMICs, low-income countries and lower middle-income countries; Mena, Middle East and North Africa.

\section{CCN systems/staffing/capacity}

Details including the numbers of CCNs in the workforce and nursing models of care were common. Two themes in particular stand out: (1) the heterogeneity in the nurse-to-patient ratios reported across regions, countries and within countries and (2) the perceptions of nurses regarding the conditions they work within.

Reported nurse-to-patient ratios were inconsistent within the included literature. Many reported ratios were equivalent to those recommended in many HIC standards for ICUs at 1:1 or 1:2. ${ }^{11}$ However, evidence of ratios as low as 1:15 was noted ${ }^{27}$ and a perceived inadequacy in the nurse-to-patient ratios to achieve patient care was common. It has been suggested that lower nurse-topatient ratios are associated with higher mortality rates in ICU ${ }^{45}$ although this is not without controversy. ${ }^{46}$ Associations between lower ratios and quality of care ${ }^{47}$ and a negative impact on nurse well-being ${ }^{48}$ have also been reported in HIC contexts.

It remains unclear what would constitute an appropriate nurse-to-patient ratio in resource-limited ICUs and warrants further research. The heterogeneity of critical care in these contexts suggests that bespoke recommendations would be required. The use of validated instruments such as the Therapeutic Intervention Scoring System or Nursing Activities Score to assess workload on a unit-based scale may be useful in determining needs.
Distribution of the literature identifying student nurses, other cadres of healthcare workers, and lay-persons providing nursing care to critically ill patients in low-income and lower-middle-

5 income countries

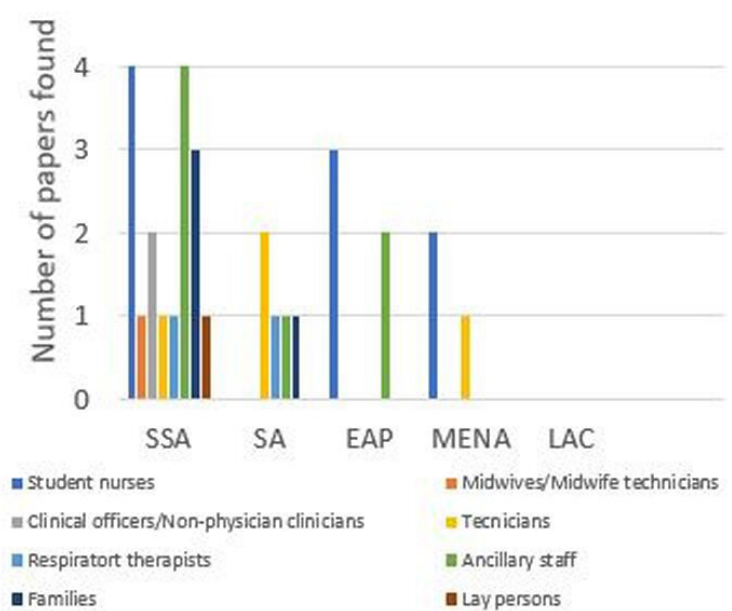

Figure 4 Distribution of the literature identifying student nurses, other cadres of healthcare workers and lay persons providing nursing care to critically ill patients in LICs/ LMICs. The chart shows the distribution of included papers that report on or discuss student nurses, other cadres of healthcare workers, and lay persons providing nursing care to critically ill patients in LICs/LMICs. EAP, East Asia and the Pacific; LAC, Latin America and the Caribbean; LICs/LMICs, low-income countries and lower middle-income countries; Mena, Middle East and North Africa.

However, even validated instruments, such as these, have limitations and do not capture non-clinical tasks or the role of the broader team in providing patient care. ${ }^{49}$

There is evidence that some nurses perceived themselves to be working in poor conditions. ${ }^{50-52}$ In the Solomon Islands, it was noted that no ICU existed, and nurses undertook all critical care of patients in wards or in non-hospital healthcare settings. ${ }^{53}$ Data from a large international survey conducted by the WFCCN found the most common theme, across all regions, was insufficient workforce numbers. ${ }^{54}$ This has been highlighted as a priority area of development by the WHO. ${ }^{9}$

In addition to the workforce constraints already discussed, basic commodities including electricity, oxygen and water may not be guaranteed. ${ }^{55}$ Work to identify appropriate technologies to build critical care capacity in resource limited contexts is, therefore, important. ${ }^{56}$

Availability and utilisation of physical resources or technologies to fulfil CCN role

In the literature from SSA, SA and MENA, advanced critical care technologies like those found in high-resource health systems were reported, examples included mechanical ventilators, ${ }^{33} 5157-59$ invasive haemodynamic monitoring $^{6061}$ and renal replacement therapy. ${ }^{36}{ }^{62}$ However, it was noted in an Indian paper that the available mechanical ventilation devices, modalities and adjunctive therapies 
Distribution of the literature identifying critical care nursing practices or tasks in low-income and lower-middle-income countries

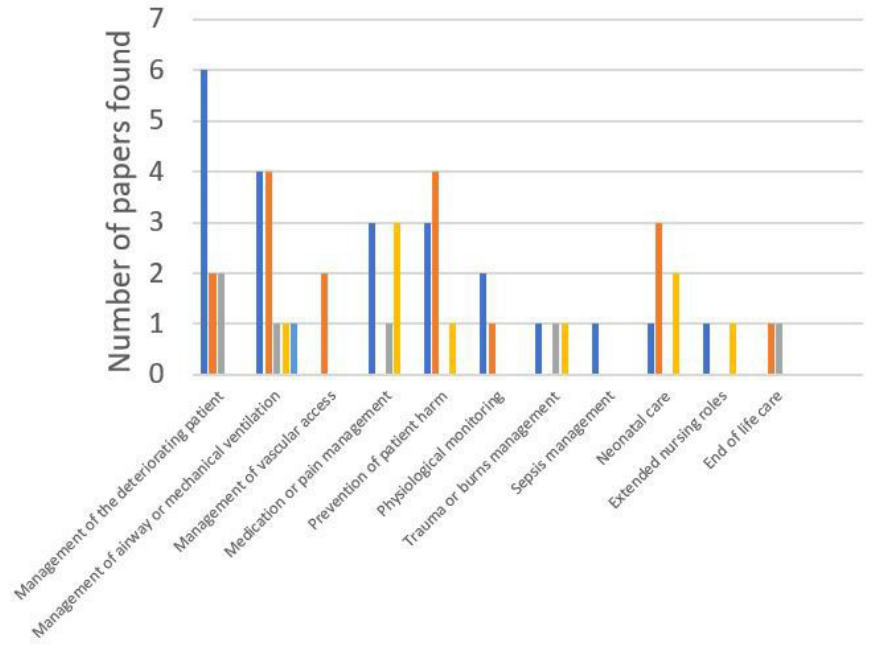

- SSA SA EAP MENA

Figure 5 Distribution of the literature identifying CCN practices or tasks in LICs/LMICs. The chart shows the distribution of included papers that report on or discuss CCN practices or tasks in LICs/LMICs. CCN, critical care nursing; EAP, East Asia and the Pacific; LAC, Latin America and the Caribbean; LICs/LMICs, low-income countries and lower middle-income countries; Mena, Middle East and North Africa.

remained underutilised due to a lack of training on their use. ${ }^{63}$ Similarly, where equipment was available, it may be old or poorly functioning in some contexts including Nepal and Sri Lanka. 5158

It should be noted that although critical care is synonymous with high technology resources in HICs, the associated high costs and need for highly trained staff may not be achievable in resource-limited settings. ${ }^{8}$ Research into what constitutes appropriate critical care technologies in resource-limited settings is important. ${ }^{56}$ However, critically ill patients exist in all hospitals, regardless of the availability of equipment and resources. Therefore, delivering critical care should not be predicated on the availability of technology or the ability to achieve all aspects of care in all settings. Instead, critical care should be based on what is appropriate and feasible in each setting. ${ }^{64}$

\section{Availability of policies or guidelines to support evidence-based practice}

Limited data spoke to policies, documentation or practice guidelines in each region. However, a common theme was a perceived absence or inadequacy of these resources; for example, in Nigeria, this absence was reported as leading to inadequate knowledge of evidence-based practices. ${ }^{65}$ In a Zambian context, it was highlighted that even when protocols existed, they were not able to be successfully implemented. However, the
Distribution of the literature identifying training and education of nurses providing critical care in lowincome and lower-middle-income countries

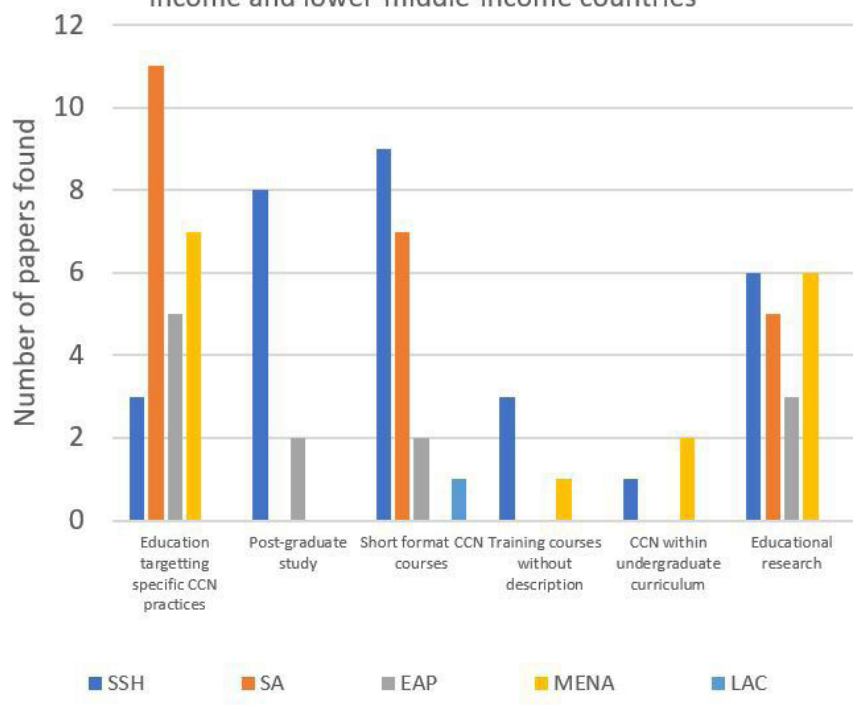

Figure 6 Distribution of the literature identifying training and education of nurses providing critical care in LICs/LMICs. The chart shows the distribution of included papers that report on or discuss CCN training and education in LICs/LMICs. CCN, critical care nursing; EAP, East Asia and the Pacific; LAC, Latin America and the Caribbean; LICs/LMICs, low-income countries and lower middle-income countries; Mena, Middle East and North Africa.

reasons for this were not described.$^{22}$ In a review by the same author literature from SSA contexts suggested that guidelines were often inappropriate having been developed in HIC's, where different presentations and challenges are experienced. ${ }^{24}$

Conversely, some documents demonstrated the presence of effective policies and practice guidelines, including the generation of locally developed documents. Examples included a comprehensive identification of key documents related to sepsis management in Uganda ${ }^{66}$ and a combination of international and locally developed guidelines for care in Nepal. ${ }^{60}$

\section{Registration and professional scope of nurses providing nursing care of critical care patients in LICs/LMICs Nursing registration and professional standards}

Little data were found relating to CCN scope of practice, standards or registration requirements. Available data from SSA, SA, EAP and MENA mostly identified the nursing boards that nurses registered under. A small number of papers from SSA offered extended details, such as the continuing professional development requirements for maintaining registration. ${ }^{24} 4352$ Research exploring CCN standards, requirements for registration; including CPD requirements and current scope of practices, is needed to guide capacity and health service development in LICs/LMICs. 
Training and continuing education available to nurses providing critical care in LICs/LMICs

\section{Formal postgraduate courses}

Specialty education in CCN is well documented in many HICs. For example, in the Australian context, a Master's degree programme exists in many nursing faculties, with exit points at graduate certificate, postgraduate diploma and master's degree ${ }^{67}$ where postbasic training was reported in resource-limited settings, only one paper from Zambia provided an overview of course structure or content and provided evidence that the available courses were validated to meet international standards. ${ }^{2468}$ This lack of detail makes comparison between countries and assessment of the quality of postbasic qualifications difficult. Therefore, presenting an opportunity for research, benchmarking and curriculum development.

A smaller subset of critical care courses were reported where nurses from low-income health systems travelled to other countries to undertake training; one example is found in Rwanda where nurses train in Kenya or South Africa. ${ }^{69}$ Caution is required to ensure training attained in this way is contextually appropriate. It was noted by Bruce $^{70}$ that CCNs returning to Mozambique following clinical internship in South Africa felt disempowered. Technologies and practices they had experienced were not achievable in their home contexts. It is also evident that healthcare workers from resource-limited countries who are able to train in HIC's frequently stay in those countries once graduated. ${ }^{71}$

It is widely noted that low wages are both a cause of dissatisfaction and a barrier to nurses pursuing postbasic qualifications in LIC/LMICs. ${ }^{72}$ Furthermore, a recent global survey of $\mathrm{CCN}$ organisations highlights that credentialling is of great importance to critical care nurses in low-income settings. ${ }^{54}$ Strategies to make postbasic training accessible and attractive to nurses providing critical care in LICs/LMICs are, therefore, important and an area that deserves attention in research and capacity development agendas.

\section{Short format critical care courses}

Many short format courses were developed in-country or developed with support from international collaborators. Some were delivered by local faculty and others by visiting international educators. Among others, the Fundamental Critical Care Support/Paediatric Fundamental Critical Care Support courses in Haiti, Kenya and Nepal, ${ }^{30} 5773$ the Sugar, Temperature, Airway, Blood pressure, Lab work and Emotional support programme ${ }^{27} 74$ and the Paediatric Assessment of Illness, Recognition and Resuscitation courses $^{75}$ were identified in SSA. In SA courses included: The Facility Based Integrated Management of Neonatal and Childhood Illnesses programme, ${ }^{76}$ the Network for Improving Critical care Skills Training (NICST) programme $\mathrm{e}^{77-79}$ and the Basic Assessment and Support in Intensive Care course. ${ }^{80} 81$

\section{Educational activities promoted by CCN societies}

Tier-3 evidence demonstrated that nursing organisations in SSA, SA and EAP promoted locally delivered educational workshops or critical care short courses. ${ }^{82-87}$ One course in Ghana was promoted as accredited and in partnership with a university nursing faculty. ${ }^{83}$ Local and regional conferences were promoted or organised by most of the organisations. ${ }^{82-89}$

\section{Educational activities targeting specific CCN practices}

A broad range of educational activities targeting specific CCN practices were noted. Some evidenced informal in-service type of education. However, some nurses in Tanzania and Egypt perceived there to be a gap in this type of job facility-based training. ${ }^{90} 91$ Literature from EAP and SA focused on task or practice-specific training in areas as diverse as crisis resource management, ${ }^{92}$ infection control practices ${ }^{93}$ or the use of physical restraints. ${ }^{94}$

\section{Access to educational resources/use of IT}

Data regarding access to learning materials were extracted. A small number of documents from SSA suggested that access to open-source journals existed, ${ }^{29}$ or that learning guides and reading materials were supplied as part of CCN courses. ${ }^{35}{ }^{95}$ However, papers from Nigeria and Uganda highlighted that a lack of access to relevant evidence and materials was experienced by nurses. ${ }^{65} 96$ Where short-format CCN courses were discussed, it was suggested that the use of low-fidelity simulation ${ }^{95}$ and using a train-the-trainer model to upskill clinical nurses in effective clinical teaching were useful strategies. ${ }^{35} \mathrm{In}$ Tanzania, it was suggested that in-service trainings were not a usually practiced ${ }^{90}$ whereas, in other SSA settings IT capabilities, including limited access to computers ${ }^{29} 62$ were perceived as constraints on the delivery of clinical education.

\section{Educational research}

Educational activities targeting specific CCN practices and broader critical care courses were both the subject of educational research in LICs/LMICs. Before and after testing of knowledge, ${ }^{21}$ measures of satisfaction and acceptability of training, ${ }^{76}$ practice change and the impact of education on clinical outcomes ${ }^{9798}$ were all noted. The broader literature suggests that continuing education for nurses in LICs/LMICs remains poorly researched. A recent narrative synthesis identified a range of strategies employed in general nurse education, not specifically CCN. ${ }^{99}$ These included train-the-trainer models, low-dose/high-frequency models and the use of multiple media; including web-based delivery for training that have been studied in LIC/LMIC contexts. However, they noted that the quality of the evidence produced was low.

Great opportunity exists to undertake focused research investigating the roles, capacity and continuing education requirements of nurses providing critical care in LICs/LMICs. Research regarding the optimal strategies for delivery of continuing education in these contexts 
is also needed. Such work is vital in the ongoing development of critical care services in resource-constrained health systems.

Addressing capacity development in LICs/LMICs is challenging. Perceived needs may be high but current assets and capacity variable. It is recommended by some that a hybrid approach should be taken where assets, capacity and needs, are assessed simultaneously, driven by the local stakeholders. ${ }^{100}$ The outcomes of such an assessment should inform contextually appropriate initiatives, that value and leverage current assets and capacity, understand the enablers and barriers to engaging in capacity development work and clearly identify where needs exist and can be addressed.

\section{Limitations}

Although the search strategy was developed to be as comprehensive as possible. Resource constraints, not least the inability to translate non-English language documents, mean it is possible that some literature was not captured. Efforts to access the websites of national health departments and nursing councils or directly contact these organisations may elucidate registration requirements, scopes and standards of practice. However, it remains unclear whether this would provide data specific to CCN. Finally, the lack of literature found in English from LICs/LMICs in LAC prevents an accurate picture of $\mathrm{CCN}$ in these contexts to be drawn.

\section{CONCLUSION}

Provision of critical care is a complex undertaking and despite commonalities and is unique to regional and socioeconomic contexts. Multidisciplinary teamwork is paramount. Yet the structure and skill levels of such teams will vary according to patient population, resources and treatments available. The findings of this study documented care of critically ill patients in specialist and nonspecialist environments. Human and physical resourcing was highly variable across regions but often reported as inadequate to meet demand within LIC/LMIC health systems. The descriptions of CCN training and skill levels were equally variable but often perceived as requiring development. Therefore, a universal definition of the CCN role in LIC/LMIC health systems is likely unhelpful. Research opportunities abound to elucidate current assets, capacity and needs of CCNs in specific LIC/LMIC contexts. Outputs from such research would be invaluable in supporting contextually appropriate capacity development programmes.

Contributors Made substantial contributions to conception and design, or acquisition of data, or analysis and interpretation of data; AM, GO'R, GW, PC. Involved in drafting the manuscript or revising it critically for important intellectual content; AM, GO'R, GW, PC. Given final approval of the version to be published. Each author should have participated sufficiently in the work to take public responsibility for appropriate portions of the content; AM, GO'R, GW, PC. Agreed to be accountable for all aspects of the work in ensuring that questions related to the accuracy or integrity of any part of the work are appropriately investigated and resolved. AM, GO'R, GW, PC. The guarantor accepts full responsibility for the work and/or the conduct of the study, had access to the data, and controlled the decision to publish. AM acts as a gaurantor.

Funding This research is supported by an Australian Government Research Training Program (RTP) Scholarship. Award/Grant number is not applicable.

Competing interests None declared.

Patient and public involvement statement No patient was involved.

Patient consent for publication Not applicable.

Ethics approval This study does not involve human participants; no ethics approval was required for this research

Provenance and peer review Not commissioned; externally peer reviewed.

Data availability statement All data relevant to the study are included in the article or uploaded as supplementary information. A full search strategy is included to allow replication.

Supplemental material This content has been supplied by the author(s). It has not been vetted by BMJ Publishing Group Limited (BMJ) and may not have been peer-reviewed. Any opinions or recommendations discussed are solely those of the author(s) and are not endorsed by BMJ. BMJ disclaims all liability and responsibility arising from any reliance placed on the content. Where the content includes any translated material, BMJ does not warrant the accuracy and reliability of the translations (including but not limited to local regulations, clinical guidelines, terminology, drug names and drug dosages), and is not responsible for any error and/or omissions arising from translation and adaptation or otherwise.

Open access This is an open access article distributed in accordance with the Creative Commons Attribution Non Commercial (CC BY-NC 4.0) license, which permits others to distribute, remix, adapt, build upon this work non-commercially, and license their derivative works on different terms, provided the original work is properly cited, appropriate credit is given, any changes made indicated, and the use is non-commercial. See: http://creativecommons.org/licenses/by-nc/4.0/.

ORCID iD

Andy Macey http://orcid.org/0000-0001-5144-104X

\section{REFERENCES}

1 Marshall JC, Bosco L, Adhikari NK, et al. What is an intensive care unit? A report of the task force of the world Federation of societies of intensive and critical care medicine. J Crit Care 2017;37:270-6.

2 Murthy S, Leligdowicz A, Adhikari NKJ. Intensive care unit capacity in low-income countries: a systematic review. PLoS One 2015;10:1-12.

3 Rungta N, Zirpe KG, Dixit SB, et al. Indian society of critical care medicine experts committee consensus statement on ICU planning and designing, 2020. Indian J Crit Care Med 2020;24:S43-60.

4 Adhikari NKJ, Fowler RA, Bhagwanjee S, et al. Critical care and the global burden of critical illness in adults. Lancet 2010;376:1339-46.

5 Vincent J-L, Marshall JC, Namendys-Silva SA, et al. Assessment of the worldwide burden of critical illness: the intensive care over nations (icon) audit. Lancet Respir Med 2014;2:380-6.

6 Vukoja M, Riviello ED, Schultz MJ. Critical care outcomes in resource-limited settings, 2018: 421-7.

7 Vukoja M, Riviello E, Gavrilovic S, et al. A survey on critical care resources and practices in low- and middle-income countries. Glob Heart 2014;9:337-42.

8 Diaz JV, Riviello ED, Papali A, et al. Global critical care: moving forward in resource-limited settings. Ann Glob Health 2019;85.

9 WHO. Global strategy on human resources for health: workforce 2030. Geneva, Switzerland: World Health Organization, 2016.

10 Aiken LH, Sloane DM, Bruyneel L, et al. Nurse staffing and education and hospital mortality in nine European countries: a retrospective observational study. Lancet 2014;383:1824-30.

11 Chamberlain D, Pollock W, Fulbrook P. ACCCN workforce standards for intensive care nursing: systematic and evidence review, development, and appraisal. Australian Critical Care 2018;31:292-302.

12 Bray K, Wren I, Baldwin A, et al. Standards for nurse staffing in critical care units determined by: the British association of critical care nurses, the critical care networks national nurse leads, Royal College of Nursing Critical Care and In-flight forum. Nurs Crit Care 2010;15:109-11.

13 Chamberlain D, Pollock W, Fulbrook P, et al. ACCCN workforce standards for intensive care nursing: systematic and 
evidence review, development, and appraisal. Aust Crit Care 2018;31:292-302.

14 Peters MDJ, Godfrey C, Mclnerney P. Scoping reviews. In: Aromataris EMZ, ed. JBI manual for evidence synthesis. JBI, 2020.

15 Tricco AC, Lillie E, Zarin W, et al. PRISMA extension for scoping reviews (PRISMA-ScR): checklist and explanation. Ann Intern Med 2018;169:467-73.

16 Macey A. The critical care nursing role in low and lower-middle income settings: a scoping review protocol 2020.

17 Pham MT, Rajić A, Greig JD, et al. A scoping review of scoping reviews: advancing the approach and enhancing the consistency Res Synth Methods 2014;5:371-85.

18 Kepes S, Banks GC, McDaniel M, et al. Publication bias in the organizational sciences. Organ Res Methods 2012;15:624-62.

19 The World Bank Group. The world by region 2018. Available: https://datatopics.worldbank.org/sdgatlas/archive/2018/the-worldby-region.html

20 Waweru-Siika W, Mung'ayi V, Misango D, et al. The history of critical care in Kenya. J Crit Care 2020;55:122-7.

21 Dongara AR, Nimbalkar SM, Phatak AG, et al. An educational intervention to improve nurses' understanding of pain in children in Western India. Pain Manag Nurs 2017;18:24-32.

22 Carter C, Snell D. Nursing the critically ill surgical patient in Zambia. Br J Nurs 2016;25:1123-8.

23 Haniffa R, De Silva AP, Iddagoda S, et al. A cross-sectional survey of critical care services in Sri Lanka: a lower middle-income country. J Crit Care 2014;29:764-8.

24 Carter C, Mukonka PS, Sitwala LJ, et al. The development of critical care nursing education in Zambia. Br J Nurs 2020;29:499-505.

25 Ufashingabire CM, Nsereko E, Njunwa KJ, et al. Knowledge and attitudes of nurses regarding pain in the intensive care unit patients in Rwanda. RWJour 2016;3:21-6.

26 Mwewa B, Mweemba P. Knowledge and utilization of ICU admission criteria and guidelines, Lusaka, Zambia. Med J Zambia 2010;37:143-52.

27 Guiles S, Lemons J, Trautman M, et al. The implementation of a neonatal nurse training program at the Riley mother baby hospita of Kenya. Newborn Infant Nurs Rev 2016;16:184-9.

28 Tadyanemhandu C, van Aswegen H, Ntsiea V. Early mobilisation practices of patients in intensive care units in Zimbabwean government hospitals - a cross-sectional study. South Afr J Crit Care 2018;34:16-21

29 Bruce JC, Dippenaar J, Schmollgruber S, et al. Advancing nursing scholarship: the Mozambique model. Glob Health Action 2017;10:1351116.

30 Macleod JBA, Jones T, Aphivantrakul P, et al. Evaluation of fundamental critical care course in Kenya: knowledge, attitude, and practice. J Surg Res 2011;167:223-30.

31 Baker T, Lugazia E, Eriksen J, et al. Emergency and critical care services in Tanzania: a survey of ten hospitals. BMC Health Serv Res 2013;13:9.

32 Okech U, Chokwe T, Mung'ayi V. The operational setup of intensive care units in a low income country in East Africa. East Afr Med $J$ 2015;92:72-80.

33 Sawe HR, Mfinanga JA, Lidenge SJ, et al. Disease patterns and clinical outcomes of patients admitted in intensive care units of tertiary referral hospitals of Tanzania. BMC Int Health Hum Rights 2014;14:26.

34 Spiwak R, Lett R, Rwanyuma L, et al. Creation of a standardized burn course for low income countries: meeting local needs. Burns 2014;40:1292-9.

35 Cunningham C, Brysiewicz P, Sepeku A, et al. Developing an emergency nursing short course in Tanzania. Afr J Emerg Med 2017;7:147-50.

36 Atumanya P, Sendagire C, Wabule A, et al. Assessment of the current capacity of intensive care units in Uganda; a descriptive study. J Crit Care 2020;55:95-9.

37 Sathish Y, Lewis LE, Noronha JA, et al. Promoting developmental supportive care in preterm infants and families in a level III neonatal intensive care unit (NICU) setting in India. Nurse Educ Pract 2019;40:102612

38 Phuma-Ngaiyaye E, Welcome Kalembo F, Kalembo FW. Supporting mothers to bond with their newborn babies: strategies used in a neonatal intensive care unit at a tertiary hospital in Malawi. Int $J$ Nurs Sci 2016;3:362-6.

39 Altimier L, Phillips RM. The neonatal integrative developmental care model: seven neuroprotective core measures for familycentered developmental care. Newborn Infant Nurs Rev 2013;13:9-22.

40 United Nations. Sustainable development goals, 2021. Available: https://sdgs.un.org/goals/goal3
41 Jazieh AR, Volker S, Taher S. Involving the family in patient care: a culturally tailored communication model. Glob J Qual Safet Healthcare 2018;1:33-7.

42 Olding M, McMillan SE, Reeves S, et al. Patient and family involvement in adult critical and intensive care settings: a scoping review. Health Expect 2016;19:1183-202.

43 Gundo R. Development, implementation and evaluation of an in-service training programme for critical care nurses in Malawi. Auckland University of Technology, 2019.

44 Dongara AR, Shah SN, Nimbalkar SM, et al. Knowledge of and attitudes regarding postoperative pain among the pediatric cardiac nursing staff: an Indian experience. Pain Manag Nurs 2015;16:314-20.

45 Driscoll A, Grant MJ, Carroll D, et al. The effect of nurse-to-patient ratios on nurse-sensitive patient outcomes in acute specialist units: a systematic review and meta-analysis. Eur $J$ Cardiovasc Nurs 2018;17:6-22

46 Margadant C, Wortel S, Hoogendoorn M, et al. The nursing activities score per nurse ratio is associated with in-hospital mortality, whereas the patients per nurse ratio is not. Crit Care Med 2020;48:3-9.

47 Falk A-C, Wallin E-M. Quality of patient care in the critical care unit in relation to nurse patient ratio: a descriptive study. Intensive Crit Care Nurs 2016;35:74-9.

48 Carayon P, Alvarado CJ, Systems Engineering Initiative for Patient Safety. Workload and patient safety among critical care nurses. Crit Care Nurs Clin North Am 2007;19:121-9.

49 Scruth $\mathrm{E}$. Nursing activities score, nurse patient ratios, and ICU mortality: its more complicated than that. Crit Care Med 2020;48:126-7.

50 Paguio JT, Banayat AC. Commentary on challenges to critical care nursing practice in the Philippines. Sgrwfccn 2018;12:8-11.

51 Limbu S, Kongsuwan W, Yodchai K. Lived experiences of intensive care nurses in caring for critically ill patients. Nurs Crit Care 2019;24:9-14.

52 Gundo R, Mearns G, Dickinson A, et al. Contextual issues that influence preparedness of nurses for critical care nursing practice in Malawi. Malawi Med J 2019;31:138-43.

53 Westcott M, Martiniuk ALC, Fowler RA, et al. Critical care resources in the Solomon Islands: a cross-sectional survey. BMC Int Health Hum Rights 2012;12:9.

54 Williams G, Fulbrook P, Kleinpell R, et al. The fifth international survey of critical care nursing organizations: implications for policy. Journal of Nursing Scholarship 2020;52:652-60.

55 Dondorp AM, lyer SS, Schultz MJ. Critical care in ResourceRestricted settings. JAMA 2016;315:753.

56 Turner HC, Hao NV, Yacoub S, et al. Achieving affordable critical care in low-income and middle-income countries. BMJ Glob Health 2019;4:e001675.

57 Kumar R, Canarie MF. Developing pediatric critical care in Kenya. Pediatric Critical Care Medicine 2019;20:1-45.

58 Charlton S, O'Reilly G, Jones T, et al. Emergency care in developing nations: the role of emergency nurses in Galle, Sri Lanka. Australasian Emergency Nursing Journal 2011;14:69-74.

59 Aloush SM, Abdelkader FA, Al-Sayaghi K, et al. Compliance of nurses and hospitals with ventilator-associated pneumonia prevention guidelines: a middle Eastern survey. J Nurs Care Qual 2018;33:E8-14.

60 Khanal A, Sharma A, Basnet S. Current state of pediatric intensive care and high dependency care in Nepal. Pediatr Crit Care Med 2016;17:1032-40.

61 Baker T, Lugazia E, Eriksen J, et al. Emergency and critical care services in Tanzania: a survey of ten hospitals. BMC Health Serv Res 2013;13:140.

62 Marzuola JM. Teaching strategies to reduce VAP at Mulago Hospital: a Capstone project, 2016.

63 Atreya MR, Lorenz JM, Narendran V. Provider perceptions of bubble continuous positive airway pressure and barriers to implementation in a level III neonatal unit in South India. Adv Neonatal Care 2018;18:500-6.

64 Riviello ED, Letchford S, Achieng L, et al. Critical care in resourcepoor settings: lessons learned and future directions. Crit Care Med 2011;39:860-7.

65 Ilesanmi RE, Olabisi P. Assessment of common interventions and perceived barriers to pressure ulcer prevention in Southwest Nigeria. J Wound Ostomy Continence Nurs 2014;41:242-6.

66 Nakate GM, Emelonye AU. Examining nursing practices for management of sepsis in low income countries: the case of Uganda. World 2018;12:2

67 Gill FJ, Leslie GD, Grech C, et al. An analysis of Australian graduate critical care nurse education. Collegian 2015;22:71-81. 
68 UNESCO. International standard classification of education. UNESCO Institute of Statistics, 2011.

69 Munyiginya P, Brysiewicz P, Mill J. Critical care nursing practice and education in Rwanda. S Afr J Crit Care 2016;32:55-7.

70 Bruce JC, Schmollgruber S, Baumann J. Intercountry master's degree in nursing: policy implications for the Mozambican health system. Int Nurs Rev 2018;65:425-33.

71 OECD. Recent trends in international migration of doctors, nurses and medical students, 2019.

$72 \mathrm{Ng}$ 'ang'a N, Byrne MW. Professional practice models for nurses in low-income countries: an integrative review. BMC Nurs 2015;14:44.

73 Hernandez J, Kioko M, Adeyinka A. Pediatric fundamentals of critical care support (PFCCS) course performance among staff from U.S. and resource-limited countries. Pediat Critic Care Med 2012;13:718.

74 Kendall AB, Scott PA, Karlsen KA. The S.T.A.B.L.E. $®$ program: the evidence behind the 2012 update. J Perinat Neonatal Nurs 2012;26:147-57.

75 MacDonell R, Koe S, Okafor I. Building resuscitation capability in low resource settings; development of the pairs course (outlining the development of a tailored paediatric resuscitation programme for low resource healthcare settings). Arch Dis Childhood 2019;104:A259.

76 Patel D, Nimbalkar S, Singh US, et al. Acceptability and implementation of FIMNCl by medical officers and staff nurses in government health institutions of Western India. Arch Dis Child 2012;97:A489-90.

77 De Silva AP, Stephens T, Welch J, et al. Nursing intensive care skills training: a nurse led, short, structured, and practical training program, developed and tested in a resource-limited setting. $J$ Crit Care 2015;30:438.e7-438.e11.

78 Stephens T, De Silva AP, Beane A, et al. Capacity building for critical care training delivery: development and evaluation of the network for improving critical care skills training (NICST) programme in Sri Lanka. Intensive Crit Care Nurs 2017;39:28-36.

79 Beane A, Stephens T, De Silva AP, et al. A collaborative approach to training ward nurses in acute care skills in resource limited settings: the nursing intensive care skills training (nicts) project. Intensive Care Med Exp 2015;3:1-2.

80 Gomersall. Basic assessment and support in intensive care, 2018. Available: https://www.aic.cuhk.edu.hk/web8/BASIC.htm

81 Gautam P, Acharya SP, Williams G. Formation of the southern Asia association for regional cooperation Federation of critical care nurses. Sgrwfccn 2018;12:6-7.

82 WFCCN. The world Federation of critical care nurses 2021. Available: http://wfccn.org

83 CCNGG. Critical Care Nurses Group Ghana - CCNGG Facebook site 2020.

84 CCNAU. Critical Care Nursing Association of Uganda - CCNAU facebook page, 2020. Available: https://www.facebook.com/ CCNAU.ORG/
85 CCNAPI. Critical care nurses association of the phillipines website, 2020. Available: http://www.ccnapi.org/

86 SSCCN. The Sri Lankan Society of critical care nurses website, 2020. Available: https://www.ssccn.org/

87 CCNAN. Critical Care Nurses Association of Nepal - CCNAN facebook page, 2020. Available: https://www.facebook.com/ CCNANNepal/

88 AFCCN. Conferences and events, 2021. Available: https://www. africanfccn.org/conferences-events

89 Nigeria NW. Nursing world Nigeria, 2020. Available: https://www. nursingworldnigeria.com/index.php

90 Mbwele B, Ide N, Mrema J, et al. Learning from health care workers' opinions for improving quality of neonatal health care in kilimanjaro region, northeast Tanzania. Ann Med Health Sci Res 2014;4:105-14.

91 Eltaybani S, Abdelwareth M, Abou-Zeid NA, et al. Recommendations to prevent nursing errors: content analysis of semi-structured interviews with intensive care unit nurses in a developing country. J Nurs Manag 2020;28:690-8.

92 Emani SS, Allan CK, Forster T, et al. Simulation training improves team dynamics and performance in a low-resource cardiac intensive care unit. Ann Pediatr Cardiol 2018;11:130-6.

93 Sharma R, Jagota R, Koushal V. Study of knowledge, awareness and practices of infection control among ICU staff of a Multispecialty tertiary level teaching Institute of North India. $J$ Health Manag 2013;15:45-56.

94 Pradhan N, Lama S, Mandal G, et al. Physical restraining: nurses knowledge and practice in tertiary care hospital of eastern Nepal. Nurs Open 2019;6:1029-37.

95 Byrne-Davis L, Slattery H, Whiteside S, et al. Efficacy and acceptability of an acute illness management course delivered to staff and students in Uganda by staff from the UK. Int Health 2015;7:360-6.

96 Kizza IB, Muliira JK. Nurses' pain assessment practices with critically ill adult patients. Int Nurs Rev 2015;62:573-82.

97 Acharya R, Bedanta Mishra S, Ipsita S, et al. Impact of nursing education on CLABSI rates: an experience from a tertiary care hospital in eastern India. Indian J Crit Care Med 2019;23:316-9.

98 Sahni N, Biswal M, Gandhi K, et al. Effect of intensive education and training of nurses on ventilator-associated pneumonia and central line-associated bloodstream infection incidence in intensive care unit at a tertiary care center in North India. Indian J Crit Care Med 2017;21:779-82.

99 Azad A, Min J-G, Syed S, et al. Continued nursing education in lowincome and middle-income countries: a narrative synthesis. BMJ Glob Health 2020;5:e001981.

100 Altschuld J, Hsin-Ling S, Lee Y-F. Needs assessment and asset/ capacity building: A promising development in practice. In: Altschuld JW, Watkins R, eds. Needs assessment: trends and a view toward the future: Wiley periodicals. , 2014: 2014, 89-103. 